\title{
Schweizerische Belegärzte-Vereinigung (SBV)
} Asmb

Ulrich Wanner

Korrespondenz:

Dr. iur. Ulrich Wanner

Sekretär der SBV

Moosstrasse 2

CH-3073 Gümligen

Tel. 0319527905

www.belegarzt.ch

\section{Entstehung}

Die Schweizerische Belegärzte-Vereinigung wurde auf Initiative einiger Ärzte im Jahr 1995 in Bern gegründet. Unter dem Namen «Schweizerische Vereinigung der Belegärzte an Privatkliniken SVBP» galt es zunächst, die Interessen der freiberuflich tätigen Ärzte, die an Privatspitälern «Betten belegten», zu bündeln und nach aussen zu vertreten. Und vermehrt sahen sich die privaten Leistungserbringer, Kliniken und Ärzte auch veranlasst, gegenüber Behörden, Institutionen, Kostenträgern und benachbarten Berufsorganisationen Position zu beziehen. Waren es zu Beginn gerade einmal 130 Gründungsmitglieder, so zeigte sich nach den zwei ersten schwierigen Jahren eine erfreuliche Entwicklung: Die SBV zählt heute fast 1700 Mitglieder aus allen Landesteilen und auch aus praktisch allen Fachgesellschaften der FMH.

\section{Zusammensetzung und Struktur}

Die SBV ist weder Regionalorganisation noch Fachgesellschaft, sondern eine «societas sui generis», ähnlich wie etwa der VLSS (Verein der Leitenden Spitalärzte der Schweiz), jedoch mit dem Unterschied, dass die SBVMitglieder ausdrücklich selbständig sind. Der überwiegende Teil der niedergelassenen Ärzte findet sich an Privatkliniken in den Kantonen Genf, Waadt, Bern, Aargau, Zürich und Tessin. Ein Vorstand aus 9 Mitgliedern vertritt - ohne statutarischen Imperativ - die Regionen. Gleichzeitig sind die dominierenden Fachbereiche Chirurgie, Orthopädie, Gynäkologie und Geburtshilfe sowie Anästhesie im Vorstand anzutreffen. Die Exekutive wird unterstützt durch ein mehrsprachiges Sekretariat. In den letzten Jahren hat die Zahl der Belegärzte an öffentlichen Spitälern stetig zugenommen. Die SBV nahm diese Entwicklung wahr und öffnete sich - mit Namensänderung und Ergänzung des Aufgabenkatalogs - auch diesen Belegärzten. Ein Vertreter der Belegärzte an öffentlichen Spitälern nimmt Einsitz im SBV-Vorstand.

\section{Aktivitäten}

Ausgerichtet auf die Bedürfnisse und Wünsche ihrer Mitglieder, setzt sich die SBV alle zwei Jahre Ziele. Diese lassen sich in Stichworten wie Qualitätssicherung, Belegarzttarif (!), Werbung für den Belegarzt, Standespolitik, Fortbildung, Information, Vertragsrecht mit Partnerinstitutionen (Spitäler, Kliniken) zusammenfassen.

Speziell zu erwähnen ist der Belegarzttarif, der nach zähem Ringen mit den Kostenträgern (ZMT/ MTK) im Jahr 2005 für den UV/MV/IV-Bereich getroffen werden konnte. Basierend auf TARMED, beinhaltet er für über 200 Diagnosen eine Pauschale, die auch eine Abgeltung der Praxiskosten während der belegärztlichen Tätigkeit im Spital beinhaltet. Zurzeit sind über 1000 Belegärzte Konzessionäre des Belegarzttarifs.

Ein sogenanntes «10-Punkte-Programm» hält Leistungen des Belegarztes gegenüber privatversicherten Patienten fest. Diese Leistungszusage, mit der Schweizerischen Patientenorganisation koordiniert und abgesprochen, ist jeweils für drei Jahre verpflichtend für SBV-Mitglieder, die sich dem Programm anschliessen.

Im gesundheitspolitischen Bereich nimmt die SBV regelmässig Stellung zu Vernehmlassungsvorlagen. Sie ist Mitglied des Schweizerischen Gewerbeverbands und pflegt Kontakte mit den ständigen Kommissionen der Eidgenössischen Räte, so etwa in den «Feierabendgesprächen» mit der Kommission für soziale Sicherheit und Gesundheit von National- und Ständerat.

\section{Ausblick}

Die Einführung der DRGs an den schweizerischen Spitälern wird direkten Einfluss auf die belegärztliche Leistungsabgeltung haben. Die SBV will sich dafür einsetzen, dass die belegärztliche Patientenbetreuung am Spital angemessen vergütet wird.

Damit verbunden sind die Entwicklungen bei der Zusatzversicherung. Zusammen mit massgeblichen Assekuranzunternehmen sollen Versicherungsangebote erarbeitet werden, die den Zusatzversicherungsbereich auch über das Jahr 2012 hinaus attraktiv erscheinen lassen. Schliesslich will die SBV bewusst die Zusammenarbeit mit Partnerorganisationen im Gesundheitswesen pflegen und die Interessen der privaten Leistungserbringer in gebündelter Form vertreten. 